\title{
Extinction of Fear-potentiated Startle: Blockade by Infusion of an NMDA Antagonist into the Amygdala
}

\author{
William A. Falls, Mindy J. D. Miserendino, and Michael Davis \\ Departments of Psychology and Psychiatry, Yale University, Abraham Ribicoff Research Facilities, Connecticut Mental \\ Health Center, New Haven, Connecticut 06508
}

Data derived from in vitro preparations indicate that NMDA receptors play a critical role in synaptic plasticity in the CNS. More recently, in vivo pharmacological manipulations have suggested that an NMDA-dependent process may be involved In specific forms of behavioral plasticity. All of the work thus far has focused on the possible role of NMDA receptors in the acquisition of responses. However, there are many examples in the behavioral literature of learninginduced changes that involve the reduction or elimination of a previously acquired response. Experimental extinction is a primary example of the elimination of a learned response. Experimental extinction is well described in the behavioral literature, but has not received the same attention in the neurobiological literature. As a result, the neural mechanisms that underlie this important form of learning are not at all understood. In the present experiments, the fear-potentiated startle paradigm was employed to begin to investigate neural mechanisms of extinction. The results show that infusion of the NMDA antagonist D,L-2-amino-5-phosphonovaleric acid (AP5) into the amygdala, a limbic structure known to be important for fear conditioning, dose-dependently blocked extinction of conditioned fear. Control experiments showed that the blockade of extinction was neither the result of the permanent disruption of amygdaloid function nor the result of decreased sensitivity of the animals to the conditioned stimulus. Infusion of AP5 into the interpositus nucleus of the cerebellum, a control site, did not block extinction. Finally, intra-amygdala infusion of a selected dose of the non-NMDA antagonist 6-cyano-7-nitroquinoxaline-2,3dione did not block extinction of conditioned fear. These results, together with a previous report from our laboratory (Miserendino et al., 1990), demonstrate the importance of the amygdala in the elaboration of conditioned fear and suggest that an NMDA-dependent process might underlie the extinction of conditioned fear.

\footnotetext{
Received July 8, 1991; revised Oct. 9, 1991; accepted Oct. 10, 1991.

We thank Lee Schlesinger for help in training animals, and T. H. Brown and co-workers, Serge Campeau, and Younglim Lee for their comments on an earlier version of the manuscript. This research was supported by NIMH Training Grant MH-18397-05 to W.A.F. and M.J.D.M. and NIH Grants MH-25624 and MH47840 , a grant from the AFOSR, and Research Scientist Development Award MH-00004 awarded to M.D.

Correspondence should be addressed to William A. Falls, Departments of Psychology and Psychiatry, Yale University Abraham Ribicoff Research Facilities, Connecticut Mental Health Center, 34 Park Street, New Haven, CT 06508.
}

Copyright (C) 1992 Society for Neuroscience $0270-6474 / 92 / 120854-10 \$ 05.00 / 0$
The search for the biological basis of learning has largely focused on response acquisition. However, the behavioral literature is replete with examples of learning phenomena that involve response reduction or inhibition, and these phenomena have played a central role in contemporary learning theory. For example, in Pavlovian fear conditioning, response acquisition occurs by pairing a neutral conditioned stimulus with an aversive stimulus. This pairing leads to a variety of behavioral effects such as freezing, autonomic changes, and fear-potentiated startle that are used to define a state of conditioned fear. If, following this training, the conditioned stimulus is repeatedly presented in the absence of the aversive stimulus (i.e., the conditioned stimulus is nonreinforced), the conditioned stimulus loses its ability to produce these behavioral effects. The reduction in conditioned fear is referred to as experimental extinction and is thought to involve the formation of a new memory rather than the passive decay or erasure of the original memory (Konorski, 1948; Estes, 1955; Rescorla, 1979). Learning phenomena that involve response reduction have not received much attention in the neurobiological literature. Because response reduction is an integral part of learning, a complete understanding of the neurobiological basis of learning will require an understanding of the mechanisms of response reduction, including experimental extinction.

Over the past few years a number of studies have supported the role of NMDA receptors in behavioral plasticity (Morris, 1989; Robinson et al., 1989; Staubli et al., 1989; Flood et al., 1990; Kim and McGaugh, 1990; Shapiro and Carmanos, 1990). Recently, NMDA receptors within the amygdala, a limbic forebrain structure known to be involved in fear (Gloor, 1960; Goddard, 1964; Sarter and Markowitsch, 1985; Kapp and Pascoe, 1986; Davis et al., 1987; LeDoux, 1987; Mishkin and Appenzeller, 1987; Gray, 1989), have been implicated in the acquisition of conditioned fear (Kim and McGaugh, 1990; Liang and Davis, 1990; Miserendino et al., 1990). For example, intraamygdala infusion of the NMDA receptor antagonist D,L-2amino-5-phosphonovaleric acid (AP5) dose-dependently blocked the acquisition of conditioned fear as assessed by potentiation of the acoustic startle response, a brainstem reflex with a neural pathway known to be directly connected with, and modulated by, the amygdala (Davis et al., 1982, 1987; Miserendino et al., 1990).

Extinction is thought to be a learning process and as such may involve NMDA receptors. Because the amygdala is critically involved in fear conditioning and because NMDA receptors within the amygdala appear to be involved in the acquisition of conditioned fear, we investigated the role of NMDA receptors within the amygdala in extinction of conditioned fear. 
Conditioned fear was assessed with the potentiated startle paradigm. In this paradigm, conditioned fear is operationally defined as an increase in the amplitude of the acoustically elicited startle response in the presence of a light-conditioned stimulus that was previously paired with shock. Fear-potentiated startle has proven to be a reliable measure of conditioned fear, as it is sensitive to anxiolytic drugs and is disrupted by anatomical lesions known to affect conditioned fear (Davis et al., 1987).

\section{Materials and Methods}

\section{Animals}

Male albino Sprague-Dawley rats (Charles River Co.) weighing between 330 and $430 \mathrm{gm}$ were used. Nonoperated rats were housed in groups of five, and cannulated rats were housed individually. All rats were maintained on a $12 \mathrm{hr}$ light $/ 12 \mathrm{hr}$ dark cycle (lights on at 7:00 AM) with food and water continuously available.

\section{General behavioral procedures}

Apparatus. Five identical aluminum and Plexiglas boxes $(30 \mathrm{~cm} \times 25$ $\mathrm{cm} \times 25 \mathrm{~cm}$ ) located on two shelves within a sound attenuating chamber were used for potentiated startle training. The floor of each box consisted of $4.8 \mathrm{~mm}$ stainless steel bars spaced $19 \mathrm{~mm}$ apart. The conditioned stimulus was provided by an $8 \mathrm{~W}$ fluorescent light located on the outside back wall of each training box. The training box was completely dark except when the conditioned stimulus was illuminated. The unconditioned stimulus was a footshock generated by five Lehigh Valley constant current shock generators located outside of the isolation chamber. Shock intensity was measured with a $1 \mathrm{~K} \Omega$ resistor across a differential channel of an oscilloscope in series with a $100 \mathrm{~K} \Omega$ resistor connected between adjacent floor bars within each training box. Current was defined as root mean square (RMS) voltage across the $1 \mathrm{~K} \Omega$ resistor where $\mathrm{mA}=0.707 \times 0.5 \times$ peak-to-peak voltage. According to this method, the shock intensity was $0.4 \mathrm{~mA}$. Background white noise was $55 \mathrm{~dB}$. The apparatus used to measure startle has been described in detail (Cassella and Davis, 1986). Briefly, five stabilimeter devices were housed on two shelves of a sound-attenuating chamber. Each stabilimeter consisted of an $8 \mathrm{~cm} \times 15 \mathrm{~cm} \times 15 \mathrm{~cm}$ Plexiglas and wire mesh cage suspended between compression springs within a steel frame. An $8 \mathrm{~W}$ fluorescent bulb identical to that used in training was located behind each stabilimeter. Cage movement resulted in displacement of an accelerometer, with the resultant voltage being proportional to the velocity of displacement. Startle amplitude was defined as the maximum accelerometer voltage that occurred during a $200 \mathrm{msec}$ period after the onset of the startle stimulus. The startle stimulus was a $50 \mathrm{msec}$ burst of white noise provided through a high-frequency speaker (Radio Shack Super Tweeter) located $10 \mathrm{~cm}$ from the back of each stabilimeter. Background white noise was $55 \mathrm{~dB}$.

Potentiated startle training and testing. In all experiments, fear-conditioning consisted of 10 presentations on each of two consecutive days of a $3.7 \mathrm{sec}$ light-conditioned stimulus that coterminated with the presentation of a $500 \mathrm{msec} 0.4 \mathrm{~mA}$ footshock. The mean intertrial interval (ITI) was 4 min (range, 3-5 min). Five days after training, rats were given a test of potentiated startle to assess their initial level of fear to the light. The rats were placed in the stabilimeter devices and, after a 5 min period during which no stimuli were administered, were given 20 initial $95 \mathrm{~dB}$ startle-eliciting noise bursts at a $30 \mathrm{sec}$ ITI followed immediately by three presentations of the startle-eliciting noise burst alone and three presentations of the startle-eliciting noise burst $3.2 \mathrm{sec}$ after the onset of the $3.7 \mathrm{sec}$ light-conditioned stimulus (light \& noise). The noise burst alone and light $\&$ noise trials were presented in a pseudorandom sequence. The mean of the last 10 initial noise-alone trials for each rat was taken as that rat's baseline startle amplitude (i.e., noise alone). Conditioned fear to the light was defined as greater startle amplitude in the presence of the light (i.e., on light $\&$ noise trials) than in the dark (i.e., the last 10 initial noise-alone trials).

Extinction. On each of the next $2 \mathrm{~d}$ following the initial test, the rats were returned to the stabilimeters, and after a $5 \mathrm{~min}$ period in which no stimuli were presented, they were given 30 presentations of the 3.7 sec light in the absence of either shock or the startle-eliciting noise burst (light-alone extinction trials). The ITI was $1 \mathrm{~min}$. The context-alone control groups remained in the stabilimeters for an equivalent period of time and no stimuli were given. The colony control group remained undisturbed in the colony room for this period of time. One day later the rats were returned to the stabilimeters and given a test for fearpotentiated startle similar to the initial test described above.

\section{Surgery}

Rats were anesthetized with chloral hydrate $(400 \mathrm{mg} / \mathrm{kg}$, i.p.) and stereotaxically implanted with bilateral guide cannulas ( 22 gauge; Plastic Products, C313G) aimed at the basolateral nucleus of the amygdala (AP $-2.4, \mathrm{ML} \pm 5.1, \mathrm{DV}-8.5$ relative to bregma) or the interpositus nucleus of the cerebellum ( $\mathrm{AP}-11.4, \mathrm{ML} \pm 2.4, \mathrm{DV}-6.3$ relative to bregma, skull flat orientation; Paxinos and Watson, 1986). Fear conditioning began 1 week after surgery.

\section{Drugs}

AP5 was dissolved in artificial cerebrospinal fluid (ACSF), and 6-cyano7-nitroquinoxaline-2,3-dione (CNQX) was dissolved in $100 \%$ dimethyl sulfoxide (DMSO). Both drugs were adjusted to a pH of 7.0. The drugs were administered bilaterally in a volume of $0.5 \mu \mathrm{l}$ via a 28 gauge inner cannula (Plastic Products, C313I) at a rate of $0.5 \mu \mathrm{l} / \mathrm{min}$.

\section{Detailed methods}

Evaluation of extinction using fear-potentiated startle: experiment 1 . To evaluate experimental extinction within this paradigm, 26 rats were given potentiated startle training as described. Following an initial test of fear-potentiated startle, the rats were divided into three groups with equivalent noise-alone and light \& noise amplitudes. On each of the next 2 consecutive days group context + lights-alone $(n=8)$ received 30 light-alone presentations in the testing apparatus, group contextalone $(n=9)$ was placed in the testing apparatus for an equivalent amount of time during which no stimuli were given, and group colony $(n=9)$ remained undisturbed in the colony room. One day later all groups were again tested for fear-potentiated startle.

The involvement of NMDA receptors within the amygdala in extinction of fear-potentiated startle: experiment 2 . To assess the role of NMDA receptors within the amygdala in extinction of fear-potentiated startle, 29 rats were implanted with bilateral guide cannulas aimed at the basolateral nucleus of the amygdala. Following recovery, the rats were trained and given an initial test of fear-potentiated startle as described in the general methods. Based upon this initial test, the rats were divided into four groups having equivalent noise-alone and light $\&$ noise amplitudes. On each of the next $2 \mathrm{~d}$, the rats were given bilateral intraamygdala infusions of either $50 \mathrm{nmol}$ AP5 or vehicle immediately before either 30 light-alone trials or equivalent exposure to the experimental context. One day later, fear-potentiated startle testing occurred in the absence of a prior infusion.

The dose dependency of the blockade of extinction by AP5: experiment 3 . To assess whether the blockade of extinction by AP5 was dose related, 24 rats were implanted with bilateral guide cannulas aimed at the basolateral nucleus of the amygdala. Following recovery the rats were trained and given an initial test of fear-potentiated startle as described above. Based upon this initial test, the rats were divided into four groups having equivalent noise-alone and light $\&$ noise amplitudes. On each of the next $2 \mathrm{~d}$, the rats were given bilateral intra-amygdala infusions of either $1.25,6.25,12.5$, or $25 \mathrm{nmol}$ AP5 immediately before 30 lightalone trials. One day later, fear-potentiated startle testing occurred in the absence of a drug infusion.

Anatomical specificity of AP5's blockade of extinction: experiment 4. To determine some anatomical specificity of AP5's blockade of extinction, 10 rats were implanted with bilateral guide cannulas aimed at the interpositus nucleus of the cerebellum. Following recovery the rats were trained and given an initial test of fear-potentiated startle as described. Based upon this initial test, the rats were divided into two groups having equivalent noise-alone and light \& noise amplitudes. On each of the next $2 \mathrm{~d}$, the rats were given bilateral intra-interpositus infusions of either $50 \mathrm{nmol}$ AP 5 or ACSF vehicle immediately before 30 light-alone trials. One day later, fear-potentiated startle testing occurred in the absence of a drug infusion.

Pharmacological specificity of AP5's blockade of extinction: experiment 5. To determine whether AP5 exerted its blockade of extinction through actions at non-NMDA receptors, eight rats were implanted with bilateral guide cannulas aimed at the basolateral nucleus of the amygdala. Following recovery the rats were trained and given an initial test 


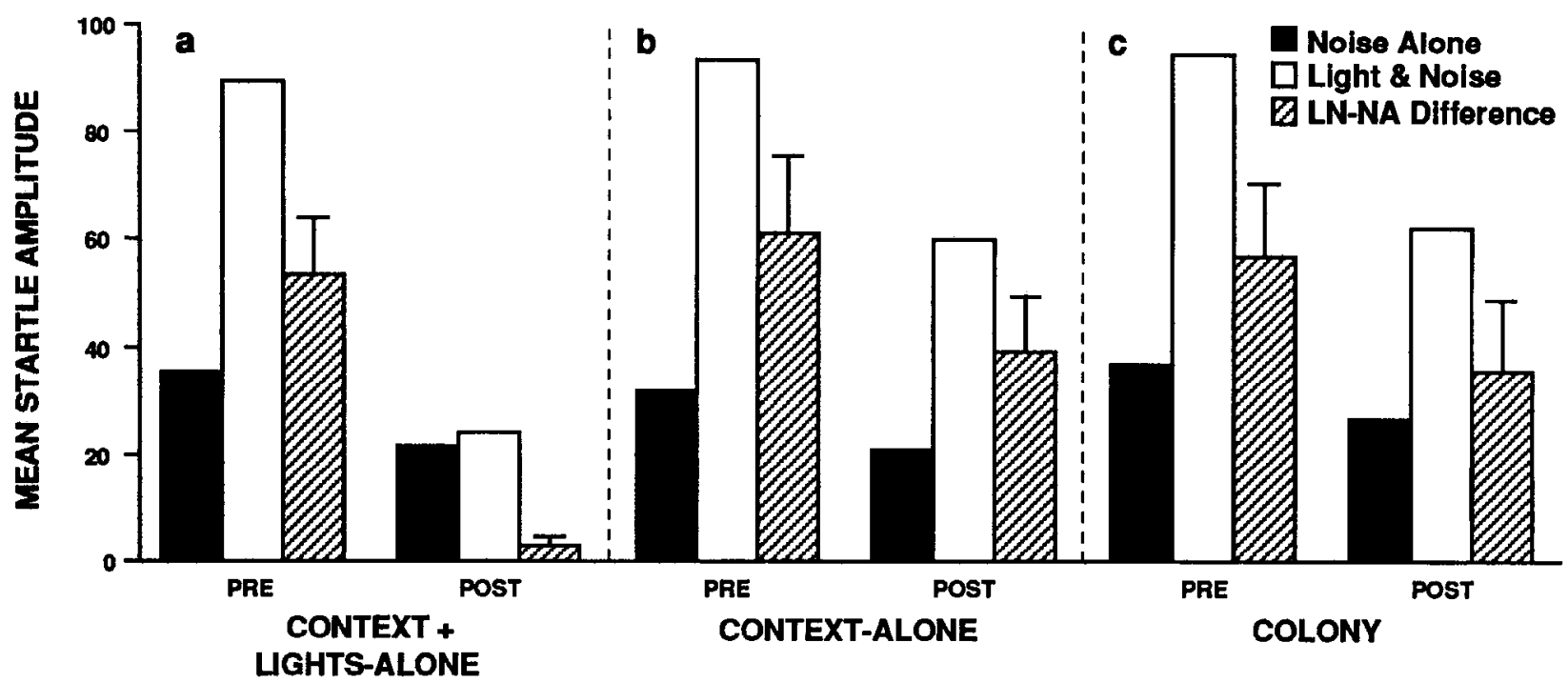

Figure 1. The amplitude of fear-potentiated startle before and after manipulations designed to reveal the relative contributions of light-alone presentations, context exposure, and the passage of time on the extinction of conditioned fear. Shown is the amplitude of startle in the presence [light \& noise $(L N)$ ] and absence [noise-alone $(N A)$ ] of the light-conditioned stimulus and the difference between the two trial types ( $L N-N A$ Difference, + SEM). The LN-NA difference score represents the magnitude of conditioned fear. The group that received context + lights-alone $(a)$ showed a significant reduction in the magnitude of fear-potentiated startle from the pretest to the posttest. In contrast, neither exposure to the context alone $(b)$ nor remaining in the colony room $(c)$ significantly reduced subsequently tested fear-potentiated startle. Hence, these groups showed significant fear-potentiated startle during both the preextinction and the postextinction tests.

of fear-potentiated startle. On each of the next $2 \mathrm{~d}$, the rats were given bilateral intra-amygdala infusions of $12.5 \mathrm{nmol}$ CNQX immediately before 30 light-alone trials. One day later, fear-potentiated startle testing occurred in the absence of a drug infusion.

\section{Histology}

At the end of each experiment, cannulated rats were killed with an overdose of chloral hydrate and perfused intracardially first with saline and then with $10 \%$ formalin in a phosphate buffer. Brains remained in a $30 \%$ sucrose formalin solution for at least $48 \mathrm{hr}$ before $40 \mu \mathrm{m}$ coronal sections were taken. Sections were stained with cresyl violet, and the locations of the injection cannulas were transcribed onto atlas plates (Paxinos and Watson, 1986).

\section{Statistical analysis}

Mean startle amplitude in the presence of the light (light \& noise), the absence of the light (noise-alone) and the difference between the two (light \& noise minus noise-alone) are presented. Statistical comparisons were made with a mixed-model analysis of variance with groups as a between-subjects factor and test (preextinction, postextinction) and trial type (noise-alone, light \& noise) as within-subjects factors. To evaluate any reduction in fear-potentiated startle resulting from group treatments, simple test $\times$ trial type interactions were analyzed separately for each of the experimental groups. Comparisons of significant simple interactions were made with $t$ tests.

\section{Results}

Evaluation of extinction using fear-potentiated startle: experiment 1

Following fear conditioning, but before light-alone presentations, the rats showed fear of the light as assessed by greater amplitude of startle in the presence versus the absence of the light (Fig. 1 $a$, PRE). However, following 60 light-alone presentations in which both the footshock and startle stimuli were omitted, there was a significant reduction (i.e., extinction) in the amplitude of fear-potentiated startle relative to the preextinction level (Fig. 1 $a$, POST). This reduction in the magnitude of fearpotentiated startle from the pretest to the posttest was supported by a significant test by trial-type interaction $[F(1,23)=12.67$; $p<0.005$ ]. Subsequent dependent $t$ tests revealed significant fear-potentiated startle at the preextinction test $[t(7)=3.99 ; p$ $<0.01]$ but not at the postextinction test $[t(7)<1]$. To test the contribution of exposure to the experimental context and the passage of time to the observed reduction in fear-potentiated startle, two additional groups were run. Figure $1, b$ and $c$, shows that reexposure to the experimental context alone, without lightconditioned stimulus prescntations, or remaining in the colony room contributes very little to the reduction in fear-potentiated startle from the preextinction to the postextinction tests [interaction $F_{\mathrm{S}}(1,23)=2.65$ and $2.51(p>0.05)$, respectively]. Subsequent $t$ tests revealed that both groups showed significant fearpotentiated startle during the preextinction test [dependent $t \mathrm{~s}(8)$ $=4.82$ and $4.50(p<0.01)$, respectively] and the postextinction test [dependent $t \mathrm{~s}(8)=3.96$ and $3.60(p<0.01)$, respectively]. Therefore, the observed reduction in fear-potentiated startle resulted from the repeated presentation of the light in the absence of shock, rather than from exposure to the experimental context or the passage of time.

\section{APS infused into the amygdala blocks extinction of fear-potentiated startle: experiment 2}

Rats receiving intra-amygdala infusion of ACSF vehicle $(n=$ 10) immediately before light-alone trials showed a significant decrease in the amount of fear-potentiated startle relative to their preextinction level [interaction $F(1,15)=10.16 ; p<0.01$; Fig. $2 a$ ]. Subsequent dependent $t$ tests revealed significant fearpotentiated startle at the preextinction test $[t(9)=3.14 ; p<$ $0.025]$ but not at the postextinction test $[t(9)=1.23 ; p>0.05]$. In contrast, rats receiving intra-amygdala infusion of $50 \mathrm{nmol}$ AP5 $(n-7)$ did not show a significant reduction in fear-potentiated startle (interaction $F<1$ ). In the AP5 group there was still significant fear-potentiated startle following light-alone trials [dependent $t(6)=3.29 ; p<0.025$; Fig. 2a]. Therefore, AP5 

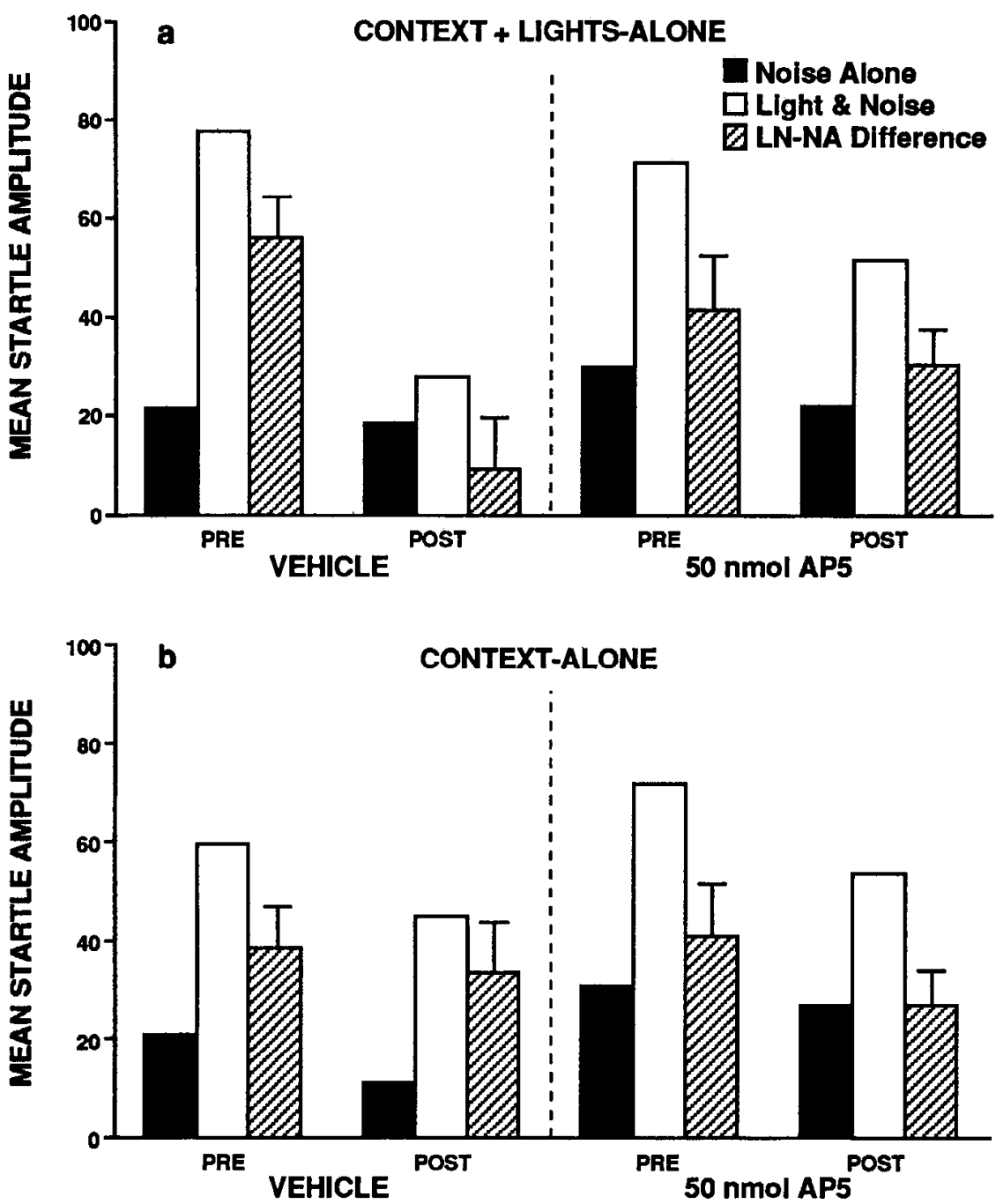

Figure 2. Effects of $50 \mathrm{nmol} \mathrm{AP5}$ on extinction of fear-potentiated startle. Shown is the amplitude of startle in the presence [light and noise (LN)] and absence [noise alone (NA)] of the light conditioned stimulus and the difference between the two trial types (LN-NA difference; + SEM). $a$, Intra-amygdala infusion of ACSF vehicle or $50 \mathrm{nmol}$ AP5 immediately prior to context + lightalone presentations. Rats that received vehicle immediately before light-alone presentations showed a significant reduction in fear-potentiated startle from the preextinction test. In contrast, rats that received AP5 did not show a significant reduction in fear-potentiated startle and had significant fear-potentiated startle during the postextinction test. $b$, Intra-amygdala infusion of ACSF vehicle or $50 \mathrm{nmol}$ AP5 immediately prior to context-alone exposure. Neither the vehicle nor the AP5 group showed a statistically significant reduction in fear-potentiated startle from the preextinction to the postextinction tests, and both groups had significant fearpotentiated startlc during both the preextinction and the postextinction tests. blocked the extinction of fear-potentiated startle that normally occurs with light-alone presentations. Moreover, the blockade appears to be complete because the modest reduction of fearpotentiated startle observed in rats infused with AP5 is comparable to the reduction observed by exposure to the experimental context alone (Fig. $1 b$ ) or to the reduction observed in rats infused with ACSF $(n=5)$ or AP5 (50 nmol; $n=7)$ immediately before exposure to the experimental context alone (Fig. $2 b$ ). Neither the vehicle group nor the AP5 context-alone group showed a statistically significant reduction in fear-potentiated startle from the preextinction to the postextinction tests [interaction $F \mathrm{~s}(1,10)=0.163$ and $1.76(p>0.05)$, respectively]. Subsequent dependent $t$ tests revealed statistically significant fear-potentiated startle during both the preextinction $[t(4)=$ $3.46, p<0.05 ; t(6)=4.37, p<0.01]$ and the postextinction tests $[t(4)=3.62, p<0.05 ; t(6)=3.44, p<0.025]$ in both the vehicle and AP5 context-alone groups, respectively.

The blockade of extinction by intra-amygdala AP5 is dose dependent: experiment 3

Figure 3 shows that the blockade of extinction by intra-amygdala infusion of AP5 was dose dependent. Specifically, doses of 25 $(n=5)$ and $12.5(n=4) \mathrm{nmol}$ were more effective in blocking extinction than the lower doses of $6.25(n=10)$ and $1.5(n=$
5) nmol. A linear contrast conducted on the mean light \& noise minus noise-alone difference scores during the postextinction test revealed a statistically reliable linear trend $[F(1,20)=4.52$; $p<0.05]$.

\section{Anatomical specificity of AP5's blockade of extinction: experiment 4}

Morris et al. (1989) have shown that the area of brain tissue affected by locally infused NMDA antagonists remains confined to a rather specific anatomical locus. To assess the anatomical specificity of AP5's blockade of extinction, rats were implanted with bilateral guide cannulas aimed at the interpositus nucleus of the cerebellum. The cerebellum is known to be important for motor learning and for fear conditioning in some situations (Supple et al., 1987; Supple and Leaton, 1990; Thompson, 1990). AP5 (50 nmol; $n=5)$ or ACSF $(n=5)$ infused into the interpositus nucleus of the cerebellum immediately prior to lightalone trials did not block extinction (Fig. 4). Analysis of the simple interaction revealed a significant test (pre-, postextinction) by trial type (noise-alone, lights \& noise) interaction $[F(1,8)$ $-10.39 ; p<0.025$ ]. Consistent with normal extinction, both the ACSF and AP5 groups displayed significant fear-potentiated startle during the preextinction test $[t \mathrm{~s}(4)=2.77$ and $2.84(p<$ $0.05)$, respectively], but neither group displayed statistically sig- 

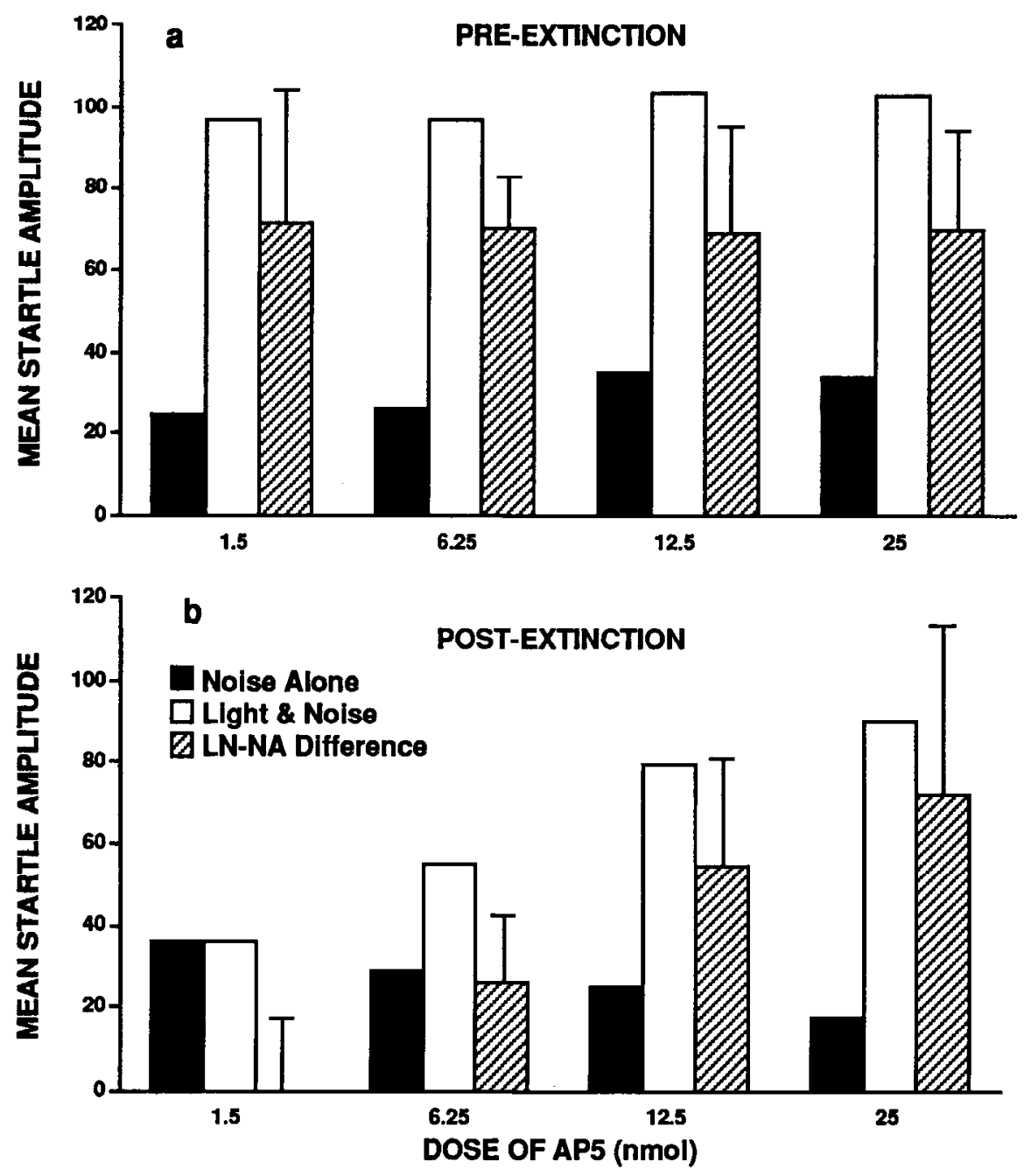

Figure 3. AP5 dosc-dependently blocks extinction of fear-potentiated startle. Shown is the amplitude of startle in the presence [light and noise (LN)] and absence [noise alone (NA)] of the light conditioned stimulus and the difference between the two trial types (LNNA difference; + SEM). $a$. Preextinction levels of fear-potentiated startle. $b$. Postextinction levels of fear-potentiated startle.

nificant fear-potentiated startle during the postextinction test [dependent $t \mathrm{~s}(4)<1$ ]. Hence, in this case, both the rats infused with AP5 and the rats infused with ACSF showed a significant reduction in fear-potentiated startle relative to their preextinction levels, indicating some anatomical specificity of the blockade of extinction by AP5.

\section{Pharmacological specificity of the blockade of extinction by AP5: experiment 5}

Because AP5 can antagonize non-NMDA receptors in addition to NMDA receptors (Honore et al., 1988), it is unclear whether AP5 exerts its blockade of extinction through the selective blockade of NMDA receptors. To test this, rats were given intraamygdala infusions of the selective non-NMDA receptor antagonist CNQX ( $12.5 \mathrm{nmol} ; n=8)$ immediately before lightalone trials (Fig. 5). Intra-amygdala CNQX did not block extinction of fear-potentiated startle, unlike an equivalent nanomolar dose of AP5. For comparison, data from the 12.5 nmol dose of AP5 described in Figure 3 are included in the left panel. Rats given intra-amygdala infusion of CNQX showed a statistically significant reduction in fear-potentiated startle from the preextinction to the postextinction tests as revealed by a reliable test by trial-type interaction $[F(1,7)=11.53 ; p<0.05]$. Subsequent dependent $t$ tests revealed significant fear-potentiated startle during the preextinction test $[t(7)=4.24 ; p<0.01]$ but not during the postextinction test $[t(7)<1]$. Because CNQX is more than 1500 times more effective than AP5 at inhibiting binding at the AMPA (i.e., non-NMDA) receptor subtype (Honore et al., 1988), it is unlikely that the blockade of extinction by AP5 results from a blockade of non-NMDA receptors.

Because damage of intrinsic amygdaloid cells is known to block the expression of fear-potentiated startle, an effect that behaviorally resembles extinction, we assessed whether intraamygdala CNQX would prevent the expression of fear-potentiated startle when administered in the absence of extinction. To test this, rats were implanted with bilateral guide cannulas aimed at the basolateral nucleus of the amygdala. Following fear conditioning and an initial test of fear-potentiated startle, the rats were infused with CNQX dissolved in 100\% DMSO (12.5 nmol; $n=6$ ) in the colony room on each of the next 2 consecutive days. CNQX administered in the colony room did not disrupt fear-potentiated startle assessed at the same time after infusion as in the previous extinction experiment [interaction $F(1,5)=$ $1.51 ; p>0.05$; data not shown]. Therefore, it is very unlikely that extinction of fear-potentiated startle under CNQX can be accounted for by a long-term disruption of amygdala function by CNQX or the DMSO vehicle.

\section{Histology}

Histological verification of the cannula placements revealed that all rats had cannulas located within $0.5 \mathrm{~mm}$ of the basolateral nucleus of the amygdala. Figure 6 is a composite drawing of 


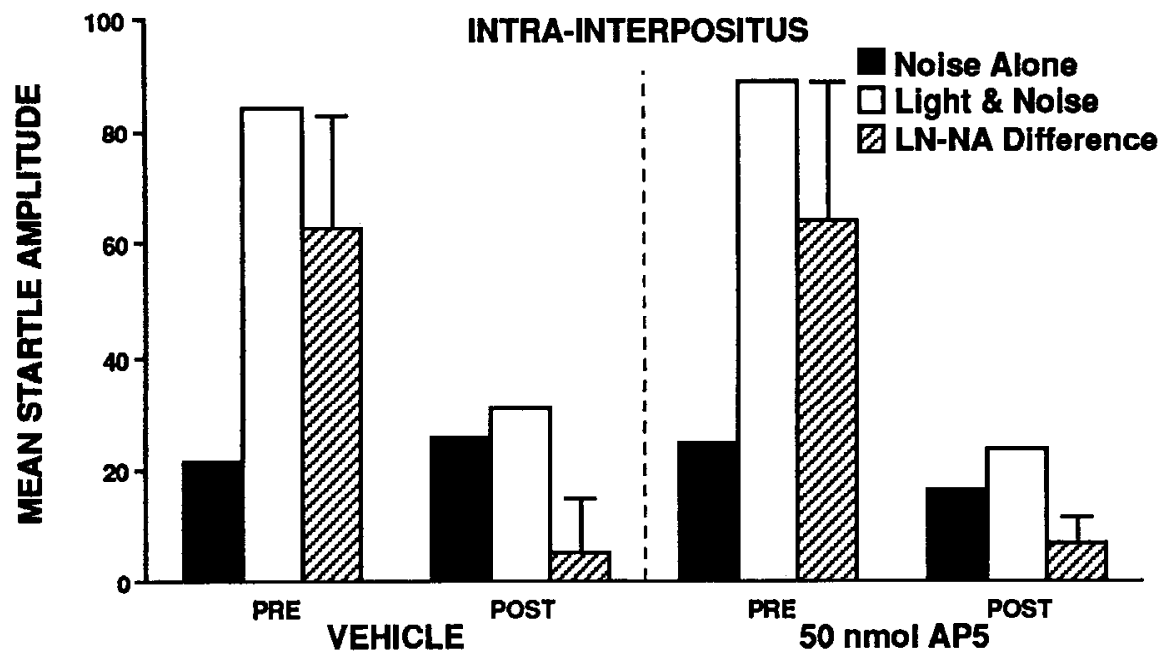

Figure 4. Effect of intra-interpositus infusion of $50 \mathrm{nmol}$ AP5 on extinction of fear-potentiated startle. Shown is the amplitude of startle in the presence [light and noise (LN)] and absence [noise alone (NA)] of the light conditioned stimulus and the difference between the two trial types (LN-NA difference; + SEM). Both the vehicle and AP5 groups showed a statistically significant reduction in fearpotentiated startle from the pretest to the posttest. Although both the ACSF and AP5 groups displayed significant fear-potentiated startle during the preextinction test, neither group displayed statistically significant fear-potentiated startle during the postextinction test. cannula tip locations. To characterize further the relationship between cannula placements and the blockade of extinction by AP5, the cannula placements from the marginally effective dose of $6.25 \mathrm{nmol} \mathrm{AP5}$ (Fig. 4) were analyzed in more detail. Rats that were judged to have one or both cannulas within the 0.5 $\mathrm{mm}$ criterion, but lateral to the basolateral nucleus of the amygdala, had virtually no blockade of extinction [90\% reduction in fcar-potentiated startlc from the preextinction to the postextinction test; interaction $F(1,8)=9.99 ; p<0.025]$. In contrast, rats with cannulas located within the basolateral nucleus of the amygdala showed a tendency toward a blockade of extinction [66\% reduction in fear-potentiated startle; interaction $F(1,8)=$ $5.05 ; p>0.05]$. The incomplete blockade of extinction in the rats with cannulas located within the basolateral nucleus of the amygdala is consistent with reduced efficacy of the lower (6.25 nmol) dose of AP5. The lack of a blockade in rats having cannulas lateral to the basolateral nucleus of the amygdala suggests that AP5 exerts its effect on extinction of conditioned fear within the basolateral nucleus of the amygdala.

\section{Controls for the possible disruptive effects of intra-amygdala infusion of $A P 5$}

Amygdala damage is known to result in a complete blockade of fcar-potentiated startlc (Hitchcock and Davis, 1986). How- ever, the blockade of extinction by AP5 in the present experiments (e.g., Figs. $2 a, 3$ ) cannot be attributed to damage produced by the intra-amygdala infusion because rats receiving intraamygdala AP5 continued to demonstrate reliable fear-potentiated startle (i.e., a blockade of extinction). To test whether intra-amygdala AP5 damaged cells that were otherwise responsible for extinction, rats that had previously shown a blockade of cxtinction by AP5 wcre administered an extended test for potentiated startle in the absence of drug infusion. Because the shock is omitted in testing for fear-potentiated startle, the extended test is similar to an extinction session. Rats that had previously received ACSF displayed no potentiated startle (i.e., extinction) at the outset of testing, whereas rats that had previously received AP5 showed substantial potentiated startle (a blockade of extinction; e.g., see Fig. $2 a$ ). However, by the end of the 30 trial test session, the rats that had previously received AP5 no longer showed fear-potentiated startle (mean light \& noise minus light-alone difference score of the final three light $\&$ noise trials $=-10.02 ; t(6)=1.51 ; p>0.05)$. Therefore, the blockade of extinction by AP5 cannot be attributed to damage to cells that are otherwise responsible for extinction.

The rats' ability to detect visual stimuli was not impaired by AP5. Rats given pretest intra-amygdala infusions of AP5 (50 nmol; $n=4)$ did not differ from vehicle controls $(n=4)$ in a

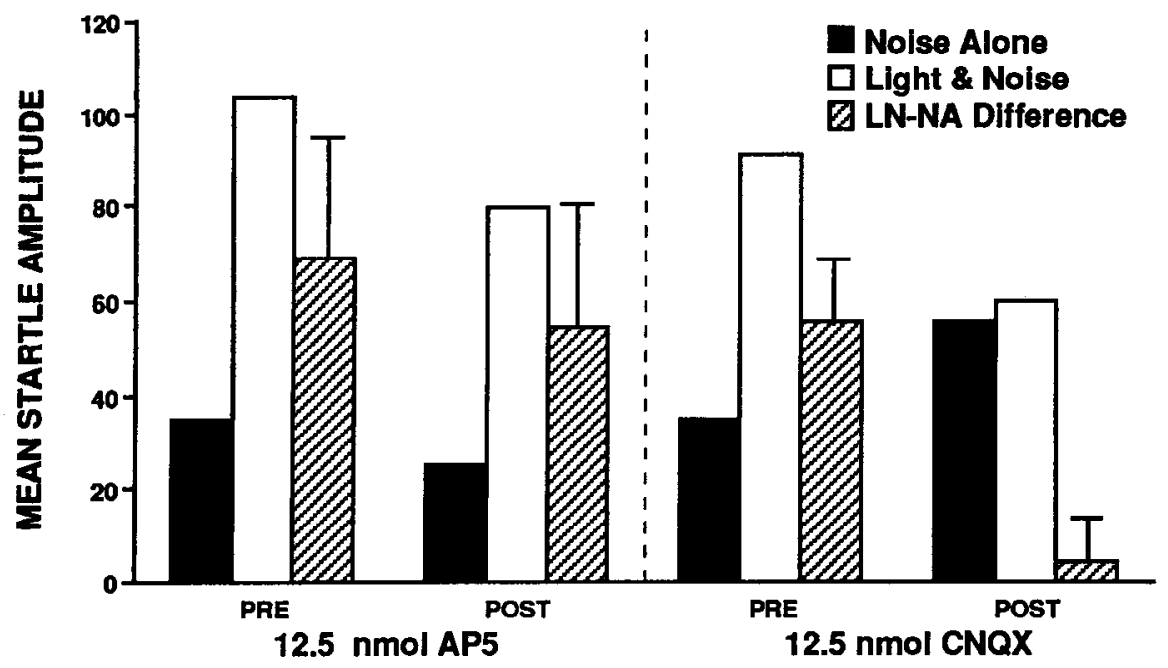

Figure 5. Intra-amygdala CNQX does not block extinction of fear-potentiated startle. Shown is the amplitude of startie in the presence [light and noise (LN)] and absence [noise alone (NA)] of the light conditioncd stimulus and the difference between the two trial types (LNNA difference; + SEM). For comparison purposes, data from the $12.5 \mathrm{nmol}$ dose of AP5 described in Figure 3 are included in the left panel. In the CNQX group there was a statistically significant reduction in fear-potentiated startle from the preextinction to the postextinction tests, with significant fear-potentiated startle during the preextinction test but not during the postextinction test. 

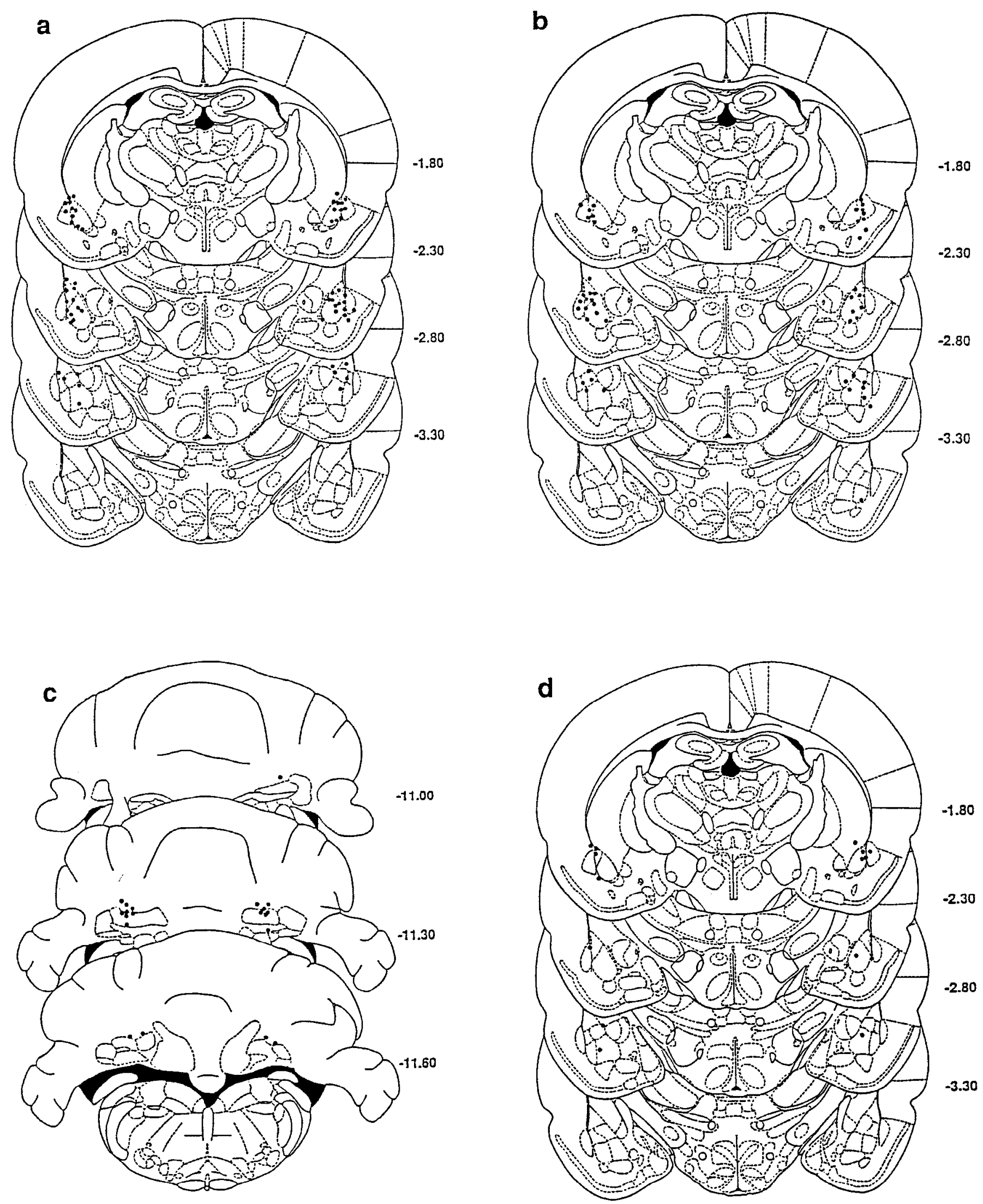

Figure 6. Serial reconstruction of cannula tip locations from experiments $2,3,4$, and 5 (panels $a, b, c$, and $d$, respectively). Coordinates are relative to bregma. 
test of visual prepulse inhibition in which a brief flash of light occurring just prior to a startle-eliciting noise burst inhibits the acoustic startle response $[F(1,7)=3.47 ; p>0.05$; data not shown; Ison and Hammond, 1971]. More importantly, Miserendino et al. (1990) have shown that intra-amygdala AP5 administered at a dose that blocked extinction in the present experiments did not block the performance of fear-potentiated startle, suggesting that AP5 does not block visual transmission at the level of the amygdala.

\section{Discussion}

The purpose of the present series of experiments was to investigate extinction of conditioned fear by first evaluating the conditions under which extinction occurs and then by assessing the role of NMDA receptors in the vicinity of the amygdala in this form of behavioral plasticity. The results show that extinction of conditioned fear required the presentation of the fear-eliciting conditioned stimulus and could be dose-dependently blocked by intra-amygdala infusion of the NMDA antagonist AP5. The blockade of extinction by AP5 showed some anatomical specificity because infusion of AP5 into the interpositus nucleus of the cerebellum failed to block extinction. However, many more infusion sites will have to be tested to determine the anatomical specificity of the amygdala in the blockade of extinction.

In contrast to AP5, intra-amygdala infusion of the competitive non-NMDA antagonist CNQX failed to block extinction. Because CNQX is over 1500 times more effective at blocking non-NMDA receptors than AP5 (Honore et al., 1988), it is unlikcly that the blockade of extinction by AP5 resulted from a blockade of non-NMDA receptors. Moreover, a separate control experiment showed that the extinction observed in rats given intra-amygdala CNQX did not result from a disruption of amygdala function by CNQX or the DMSO vehicle. However, because of solubility constraints only one dose of CNQX was used. Therefore, the possible role of non-NMDA receptors in extinction remains to be determined.

In a previous experiment, our laboratory has shown that intraamygdala infusion of AP5 does not disrupt performance of fearpotentiated startle using a visual conditioned stimulus. Therefore, the rat's ability to detect the visual stimulus, which would be required for extinction, was probably not impaired by intraamygdala AP5.

Together, these results suggest that some NMDA-dependent process in the vicinity of the amygdala may be responsible for the extinction of conditioned fear.

\section{State-dependent extinction}

Learning that occurs in the presence of a drug may not be evident in the undrugged state (Overton, 1985). Drug-induced statedependent acquisition has been observed in some situations but not in others (e.g., Overton, 1966; Henrickson and Jarbe, 1971; Ziskind and Amit, 1974; Cahill et al., 1986; Kim et al., 1991). State-dependent extinction has also been reported (e.g., Cunningham, 1979; Bouton et al., 1990). Thus, it is possible that in the present experiment, the apparent blockade of extinction by intra-amygdala AP5 did not result from a blockade of learning but from a failure to transfer the extinction memory from the AP5 drugged state to the nondrugged state (i.e., from extinction to the postextinction test). Although state-dependent extinction cannot be ruled out, it should be noted that such an effect would be the result of a state induced through the blockade of NMDA receptors in the vicinity of the amygdala. Further experiments are needed to determine whether state-dependent learning can account for the present data.

\section{Mechanisms of extinction: behavioral considerations}

The form of learning that occurs during extinction is a matter of debate within the behavioral literature. Although several different theoretical mechanisms have been proposed, two general classes of theory have emerged (cf. Wagner and Rescorla, 1972). Extinction has been explained in terms of either an "erasure" of the original associations that led to the production of the conditioned response (e.g., Estes, 1955) or the acquisition of new associations that compete with or "mask" the expression of the still-intact rcsponse-producing associations (e.g., Konorski, 1948). Both of these hypotheses hold that new learning occurs as a result of nonreinforcement. However, they make very different predictions regarding the fate of the conditioned response producing associations. The erasure hypothesis predicts that following nonreinforcement, the response-producing associations no longer exist and therefore the conditioned response can no longer be performed. On the other hand, the masking hypothesis predicts that the response-producing associations remain after nonreinforcement and therefore, if it were possible to temporarily remove the masking associations, the conditioned response could be performed. Behavioral experiments have attempted to evaluate these alternatives by assessing whether the conditioned response remains after extinction.

Several lines of evidence suggest that the original associations arc intact following extinction. For example, Bouton and colleagues (Bouton and King, 1983, 1986; Bouton and Bolles, 1985) have shown that the expression of extinction is specific to the stimulus context in which nonreinforcement occurred. Therefore, placing the animal into a context different from the one in which nonreinforcement occurred results in a return of the conditioned response. In addition, several experiments have shown that the simple re-presentation of the unconditioned stimulus following extinction is sufficient for reinstating extinguished responding to some preextinction level (Pavlov, 1927; Rescorla and Heth, 1975; Bouton and Bolles, 1979). We have replicated this effect using fear-potentiated startle (W. A. Falls and M. Davis, unpublished observations).

\section{Mechanisms of extinction: neurobiological considerations}

The results of the present experiments suggest that an NMDAdepcndent mcchanism in the vicinity of the amygdala underlies extinction of conditioned fear, a different form of behavioral plasticity than has previously been examined (see introductory remarks). Because a great deal of emphasis has been placed on the possibility that mechanisms derived in vitro may underlie behavioral plasticity, it is useful to begin to consider how mechanisms derived from in vitro experimentation may help to generate hypotheses concerning this different form of behavioral plasticity. One of the most promising models of learning in vertebrates is long-term potentiation (LTP). LTP is an activitydependent increase in synaptic efficacy that in certain hippocampal synapses is dependent upon NMDA receptor activation (Collingridge and Bliss, 1987; Brown et al., 1988; Nicoll et al., 1988). LTP has been observed in the amygdala both in vitro (Chapman et al., 1990) and in vivo (Clugnet and LeDoux, 1990). Because NMDA antagonists infused into the amygdala prevent extinction, it is possible that an LTP-likc process in the vicinity of the amygdala may underlie extinction of conditioned fear. 
Given this, the interesting question becomes how an increase in synaptic efficacy (i.e., LTP) can lead to a reduction in conditioned fear.

One of the very first behavioral theories of extinction proposed that extinction resulted from the development of inhibition that acted to oppose the existing excitation (Konorski, 1948). The plasticity underlying extinction may involve an activity-dependent (i.e., LTP-like) increase in synaptic efficacy of inhibitory interneurons in the vicinity of the amygdala that serve to inhibit cells that are otherwise responsible for the performance of conditioned fear. In fact, recent evidence has shown that NMDA-dependent LTP of IPSPs does occur (Stevens and Cotman, 1991). The amygdala is known to contain a high density of GABAergic interneurons (Le Gal La Salle et al., 1978; Carlsen, 1988) that can be activated by excitatory amino acids (Rainnie et al., 1991). However, it remains to be seen whether their responsiveness to afferent input can undergo potentiation and whether inactivating the putative inhibition, perhaps through intra-amygdala infusion of GABAergic antagonists, will reversibly block the cxpression of extinction.

Alternatively, the plasticity underlying extinction may involve an activity-dependent increase in synaptic efficacy of $e x$ citatory neurons in the vicinity of the amygdala. These neurons in turn may initiate an extra-amygdaloid circuit that inhibits cells that are otherwise responsible for the performance of conditioned fear. In fact, recent work has suggested that visual and auditory cortex may be important components of a neural circuit responsible for extinction of conditioned fear (LeDoux et al., 1989; Teich et al., 1989). Work is now underway in our laboratory to determine whether circuits extrinsic to the amygdala mediate extinction of fear-potentiated startle.

A decrease in synaptic efficacy is an alternative candidate mechanism for extinction. Long-term depression (LTD) of synaptic responses has been observed in the hippocampus and cortex (Abraham and Goddard, 1983; Levy and Steward, 1983; Bear and Cooper, 1989; Chattarji et al., 1989; Stanton and Sejnowski, 1989; Artola et al., 1990), and several authors have proposed that LTD may be the cellular mechanism for weakening behavioral responses (Teyler and Discenna, 1984; Artola et al., 1990; Goldman et al., 1990). However, because extinction does not seem to result from an erasure of the original associations, it is difficult to understand how extinction could result from a depression of potentiated synapses (i.e., reversal of LTP). Alternatively, extinction might result from a depression of nonpotentiated synapses that might normally carry conditioned stimulus information to the same postsynaptic cell that underwent LTP during excitatory conditioning. If the strength of the conditioned response reflected the net result of both depressed and potentiated synaptic inputs to this postsynaptic cell, LTD would compete with LTP to reduce the production of the conditioned response. Importantly, however, the original potentiation would remain intact, cven though the overall output of the system would be reduced. Hence, treatments that temporarily reversed LTD would result in a reinstatement of the original associations. LTD in the hippocampus is blocked by AP5 in some situations (Abraham and Wickens, 1991; Desmond et al., 1991 ) but not in others (Chattarji et al., 1989; Stanton and Sejnowski, 1989; Stanton et al., 1991). Therefore, it remains to be seen whether LTD can be induced in the amygdala and whether it can be blocked by AP5.

In summary, extinction is an integral part of learning. Therefore, a complete understanding of the neurobiological basis of learning requires an understanding of the mechanisms of extinction. The present results indicate that extinction of conditioned fear is a learning process that appears to involve an NMDA-dependent mechanism in the vicinity of the amygdala. Although it is not yet clear whether or not this mechanism is similar to LTP or LTD, the present results provide further evidence that excitatory amino acids of the NMDA subtype contribute importantly to behavioral plasticity.

\section{References}

Abraham WC, Goddard GV (1983) Asymmetrical relationships between homosynaptic long-term potentiation and heterosynaptic longterm depression. Nature 305:717-719.

Abraham WC, Wickens JR (1991) Heterosynaptic long term depression is facilitated by blockade of inhibition in area CAl of the hippocampus. Brain Res 546:336-340.

Artola A, Brocher S, Singer W (1990) Different voltage-dependent thresholds for inducing long-term depression and long-term potentiation in slices of rat visual cortex. Nature 347:69-72.

Bear MF, Cooper LN (1989) Molecular mechanisms for synaptic modification in the visual cortex: interactions between theory and experiment. In: Neuroscience and connectionist theory (Gluck MA, Rumelhart DE, eds), pp 65-93. Hillsdale, NJ: Erlbaum.

Bouton ME, Bolles RC (1979) Role of contextual stimuli in reinstatement of extinguished fear. J Exp Psychol [Anim Behav] 5:368-378.

Bouton ME, Bolles RC (1985) Context, event-memories, and extinction. In: Context and learning (Balsam PD, Tomie A, eds), pp 133166. Hillsdale, NJ: Erlbaum.

Bouton ME, King DA (1983) Contextual control of conditioned fear: tests for the associative value of the context. J Exp Psychol [Anim Behav] 9:248-256.

Bouton ME, King DA (1986) Effect of context with mixed histories of reinforcement and nonreinforcement. J Exp Psychol [Anim Behav] $12: 4-15$.

Bouton ME, Kenney FA, Rosengard C (1990) State-dependent fear extinction with two benzodiazepine tranquilizers. Behav Neurosci 104:44-55.

Brown TH, Chapman PF, Kairiss EW, Keenan CL (1988) Long-term synaptic potentiation. Science 242:724-728.

Cahill L, Brioni J, Izquierdo I (1986) Retrograde memory enhancement by diazepam: its relation to anterograde amnesia, and some clinical implications. Psychopharmacology 90:554-556.

Carlsen J (1988) Immunocytochemical localization of glutamate decarboxylase in the rat basolateral amygdaloid nucleus, with special reference to GABAergic innervation of amygdalostriatal projection neurons. J Comp Neurol 273:513-526.

Cassella JV, Davis M (1986) The design and calibration of a startle measurement system. Physiol Behav 36:377-383.

Chapman PF, Kairiss EW, Keenan CL, Brown TH (1990) Long-term synaptic potentiation in the amygdala. Science 6:271-278.

Chattarji S, Stanton PK, Sejnowski TJ (1989) Commissural synapses, but not mossy fiber synapses, in the hippocampal field CA3 exhibit associative long-term potentiation and depression. Brain Res 495: 145-150.

Clugnet MC, LeDoux JE (1990) Synaptic plasticity in fear conditioning circuits: induction of LTP in the lateral nucleus of the amygdala by stimulation of the medial geniculate body. J Neurosci 10:2818-2824.

Collingridge GL, Bliss TVP (1987) NMDA receptors-their role in long-term potentiation. Trends Neurosci 10:288-293.

Cunningham CL (1979) Alcohol as a cue for extinction: state dependency produced by conditioned inhibition. Anim Learn Behav 7: 45-52.

Davis M, Gendelman DS, Tischler MD, Gendelman PM (1982) A primary acoustic startle circuit: lesion and stimulation studies. J Neurosci 6:791-805.

Davis M, Hitchcock J, Rosen JB (1987) Anxiety and the amygdala: pharmacological and anatomical analysis of the fear-potentiated startle paradigm. In: The psychology of learning and motivation (Bower GH, ed). New York: Academic.

Desmond NL, Colbert CM, Zhang DX, Levy WB (1991) NMDA receptor antagonists block the induction of long term depression in the hippocampal dentate gyrus of the anesthetized rat. Brain Res 552: 93-98. 
Estes WK (1955) Statistical theory of spontaneous recovery and regression. Psychol Rev 62:145-154.

Flood JF, Baker ML, Davis JL (1990) Modulation of memory processing by glutamic acid receptor antagonists. Brain Res 521:197202.

Gloor P (1960) Amygdala. In: Handbook of physiology, Sec I, Neurophysiology (Field J, ed), pp 1395-1420. Washington, DC: American Physiological Society.

Goddard GV (1964) Functions of the amygdala. Pyschol Bull 62:89109.

Goldman RS, Chavez-Noriega LE, Stevens CF (1990) Failure to reverse long-term potentiation by coupling sustained presynaptic activity and $N$-methyl-D-aspartate receptor blockade. Proc Nall Acad Sci USA 87:7165-7169.

Gray TS (1989) Autonomic neuropeptide connections of the amygdala. In: Hans Selye symposia on neuroendocrinology and stress, Vol 1 (Tache Y, Morley JE, Brown MR, eds), pp 92-106. New York: Springer.

Henrickson BG, Jarbe T (1971) Effects of diazepam on conditioned avoidance learning in rats and its transfer to normal state conditions. Psychopharmacologia 20:186-190.

Hitchcock JM, Davis M (1986) Lesions of the amygdala, but not of the cerebellum or red nucleus, block conditioned fear as measured with the potentiated startle paradigm. Bchav Ncurosci 100:11-22.

Honore T, Davis SN, Drejer J, Fletcher EJ, Jacobsen P, Lodge D, Nielsen FE (1988) Quinoxalinediones: potent competitive nonNMDA glutamate receptor antagonists. Science 241:701-703.

Ison JR, Hammond GR (1971) Modification of the startle reflex in the rat by changes in the auditory and visual environments. J Comp Physiol Psychol 75:435-452.

Kapp BS, Pascoe JP (1986) Correlation aspects of learning and memory: vertebrate model systems. In: Learning and memory: a biological view (Martinez JL, Kesner RP, eds), pp 399-440. New York: Academic.

Kim JJ, DeCola JP, Landeira-Fernandez J, Fanselow MS (1991) $N$-methyl-D-aspartate receptor antagonist APV blocks acquisition but not expression of fear conditioning. Behav Neurosci 105:126-133.

Kim M, McGaugh JL (1990) Microinfusion of an $N$-methyl-D-aspartate antagonist into the amygdala impairs avoidance learning in rats. Soc Neurosci Abstr 16:316.8.

Konorski J (1948) Conditioned reflexes and neuronal organization. London: Cambridge UP.

LeDoux JE, ed (1987) Emotion. Washington, DC: American Physiological Society.

LeDoux JE, Romanski L, Xagoraris A (1989) Indelibility of subcortical memories. J Cogn Neurosci 1:238-243.

Le Gal La Salle G, Paxinos G, Ben-Ari Y (1978) Neurochemical mapping of GABAergic systems in the amygdaloid complex and bed nucleus of the stria terminalis. Brain Res 155:397-403.

Levy WB, Steward O (1983) Temporal contiguity requirements for long-term associative potentiation/depression in the hippocampus. Neuroscience 8:791-797.

Liang KC, Davis M (1990) Intra-amygdala injection of $N$-methyl-Daspartate receptor antagonists impairs memory in an inhibitory avoidance task. Soc Neurosci Abstr 16:316.7.

Miserendino MJD, Sananes CB, Melia KR, Davis M (1990) Blocking of acquisition but not expression of conditioned fear-potentiated starthe by NMDA antagonists in the amygdala. Nature 345:716-718.

Mishkin M, Appenzeller T (1987) The anatomy of memory. Sci Am 256:80-89.

Morris RGM (1989) Synaptic plasticity and learning: selective impairment of learning in rats and blockade of long-term potentiation in vivo by the $N$-methyl-D-aspartate antagonist AP5. J Neurosci 9: 3040-3057.

Morris RGM, Halliwell RF, Bowery N (1989) Synaptic plasticity and learning: do different kinds of plasticity underlie different kinds of learning? Neuropsychologia 27:41-59.

Nicoll RA, Kauer JA, Malenka RC (1988) The current excitement in long-term potentiation. Neuron 1:97-103.

Overton DA (1966) State-dependent learning effects produced by depressant and atropine-like drugs. Psychopharmacologia 10:6-31.

Overton DA (1985) Contextual stimulus effects of drugs and internal states. In: Context and learning (Balsam PD, Tomie A, eds), pp 357384. Hillsdale, NJ: Erlbaum.

Pavlov IP (1927) Conditioned reflexes. Oxford: Oxford UP.

Paxinos G, Watson C (1986) The rat brain. Orlando, FL: Academic.

Rainnie DG, Asprodini EK. Shinnick-Gallagher P (1991) Inhibitory transmission in the basolateral amygdala. J Neurophysiol 66:99-109.

Rescorla RA, ed (1979) Conditioned inhibition and excitation. Hillsdale, NJ: Erlbaum.

Rescorla RA, Heth CD (1975) Reinstatement of fear to an extinguished conditioned stimulus. J Exp Psychol [Anim Behav] 1:88-96.

Robinson GS, Crooks GB, Shinkman PG, Gallagher M (1989) Behavioral effects of MK-801 mimic deficits associated with hippocampal damage. Psychobiology 17:156-164.

Sarter M, Markowitsch HJ (1985) Involvement of the amygdala in learning and memory: a critical review with emphasis on anatomical relations. Behav Neurosci 99:342-380.

Shapiro ML, Carmanos Z (1990) NMDA antagonist MK-801 impairs acquisition but not performance of spatial working and reference memory. Psychobiology 18:231-243.

Stanton PK, Sejnowski TJ (1989) Associative long-term depression in the hippocampus induced by Hebbian covariance. Nature 339: 215-218.

Stanton PK, Chattarji S, Sejnowski TJ (1991) 2-Amino-3-phosphonoproprionic acid, an inhibitor glutamate-stimulated phosphoinositide turnover, blocks induction of homosynaptic long term depression, but not potentiation, in rat hippocampus. Neurosci Lett 127:61-66.

Staubli U, Thibault O, DiLorenzo M, Lynch G (1989) Antagonism of NMDA receptors impairs acquisition but not retention of olfactory memory. Behav Neurosci 103:54-60.

Stevens DR, Cotman CW (1991) Long-term potentiation of excitatory and slow inhibitory synaptic potentials in the hippocampal-septal projection of the rat. Brain Res 558:120-122.

Supple WF, Leaton RN (1990) Lesions of the cerebellar vermis and cerebellar hemispheres: effects on heart rate conditioning in rats. Behav Neurosci 104:934-937.

Supple WF, Leaton RN, Fanselow MS (1987) Effects of cerebellar vermal lesions on species specific fear responses, neophobia, and taste aversion learning in rats. Physiol Behav 39:579-586.

Teich AH, McCabe PM, Gentile CC, Schneiderman LS, Winters RW, Liskosky DR, Schneiderman N (1989) Auditory cortex lesions prevent the extinction of heart rate conditioning to tonal stimuli in rabbits. Brain Res 480:210-218.

Teyler TJ, Discenna P (1984) Long-term potentiation as a candidate mnemonic device. Brain Res Rev 7:15-28.

Thompson RF (1990) Neural mechanisms of classical conditioning. Philos Trans R Soc Lond [Biol] 329:161-170.

Wagner AR, Rescorla RA, eds (1972) Inhibition in Pavlovian conditioning. London: Academic.

Ziskind D, Amit Z (1974) Resistance to extinction of an avoidance response in rats following the administration of chlorodiazepoxide (Librium) or diazepam (Valium). Psychopharmacologia 38:231-238. 